Article

\title{
Strengthening External Emergency Assistance for Managing Extreme Events, Systemic, and Transboundary Risks in Asia
}

\author{
Sivapuram Venkata Rama Krishna Prabhakar ${ }^{1, *}$, Kentaro Tamura ${ }^{2}$, Naoyuki Okano ${ }^{1}$ and Mariko Ikeda ${ }^{2}$ \\ ${ }^{1}$ Adaptation and Water Group, Institute for Global Environmental Strategies, Japan; \\ E-Mails: prabhakar@iges.or.jp (S.V.R.K.P.), okano@iges.or.jp (N.O.) \\ ${ }^{2}$ Climate and Energy Group, Institute for Global Environmental Strategies, Japan; E-Mails: tamura@iges.or.jp (K.T.), \\ marikoikeda1@gmail.com (M.I.) \\ * Corresponding author
}

Submitted: 30 April 2021 | Accepted: 18 August 2021 | Published: 22 October 2021

\begin{abstract}
External emergency assistance (EEA) provided in the aftermath of a disaster has costs and benefits to the donor and recipient countries. Donors benefit from quick recovery feedback effects from the trade and cultural links, and recipient countries have additional resources to manage the emergency. However, EEA costs could outweigh the benefits. Costs include dependency, low development of risk reduction capacity, and staff burdened with managing the assistance as opposed to managing the recovery. Current efforts to reduce dependency on EEA are not sufficient; they are based on limited past experiences with extreme events and are not based on the understanding of future risks. In this article, we present the concept of a climate fragility risk index showing factors that affect a country's predisposition to be fragile to climate change threats and we suggest that countries with a high climate fragility risk index tend to depend on EEA. Further, the article presents the concept of critical thresholds for extreme events as a metric to identify possible dependency on EEA. In addition, based on expert and policy consultations organized in the Philippines and Pakistan, we identify measures that can enhance the effectiveness of EEA including targeted EEA provision, better integration of lessons learned from the relief stage into the rest of the DRR operations, proper documentation of past assistance experiences and consideration of these lessons for the improvement of EEA in the future, as well as developing tools such as critical threshold concepts that can better guide the donor and recipient countries on more effective delivery of EEA.
\end{abstract}

\section{Keywords}

climate change adaptation; climate security; disaster risk reduction; external emergency assistance; extreme events

\section{Issue}

This article is part of the issue "Climate Change and Security" edited by Yasuko Kameyama (National Institute for Environmental Studies, Japan) and Yukari Takamura (University of Tokyo, Japan).

(C) 2021 by the authors; licensee Cogitatio (Lisbon, Portugal). This article is licensed under a Creative Commons Attribution 4.0 International License (CC BY).

\section{Introduction}

Climate change can exacerbate extreme weather events, putting severe stress on the disaster risk management capacity of affected countries (IPCC, 2012). Such countries may require more external emergency assistance (EEA), especially those with seriously impaired capacity to manage disasters. This can then put an additional burden on the national budgets of EEA donor countries.
As a result, there is an emergent view that the EEA has costs and benefits for both the donor and recipient countries, and that such assistance can have climate security implications. However, there has not been much research on identifying specific climate security implications of increased EEA needs, and how best the EEA can be managed in such a way that both the donor and recipient countries can maximize their climate security. This necessitates a revisit of the EEA in terms of climate 
security. Viewing the issues associated with extreme events and EEA through the lens of climate security can help us to move away from a short-term thinking paradigm towards long-term thinking, with an emphasis on risk communication and risk mitigation.

EEA has significant implications for both the recipient and donor countries. EEA, if not designed well, may cause recipient countries to become dependent on such assistance. Conversely, EEA is an economic cost to the donor countries, and it is a lost economic opportunity that the donor country could have invested elsewhere with better outcomes for its people. Hence, improving the EEA is beneficial to both donor and recipient countries.

Keeping the above background in view, this article explores the possibilities for enhancing the effectiveness of EEA received by countries affected by extreme weather events. Towards this objective, the article explores the linkage between the climate fragility of a country and the development status of that country, by developing a climate fragility risk index (CFRI). Further, the article presents a critical threshold idea for the delivery of EEA to the countries affected by extreme weather events. Based on a set of stakeholder workshops organized in the Philippines and Pakistan, the article goes on to present various means for strengthening the long-term risk reduction learning from EEA experiences of recipient and donor countries.

\section{Current Status of External Emergency Assistance}

Every year, millions of dollars are being spent on EEA. Between 2000 and 2019, Asian countries received emergency assistance to the tune of $\$ 100$ billion (UN Office for the Coordination of Humanitarian Affairs [UN OCHA], 2021). In addition to financial resources, countries are also employing their military to deliver disaster relief related services. A survey conducted by the American Security Project (2012) indicates that militaries in more than $70 \%$ of countries around the world have humanitarian assistance and relief as a critical mission. The role of the military in disaster assistance may increase in the future, putting such personnel in high demand and possibly escalating the cost of humanitarian assistance due to military deployment.

The figures reported in terms of EEA often do not reflect the time and resources spent by the donor countries in delivering assistance to an endpoint. These resources include the time spent by the ministries and relevant government agencies in deliberating and designing the assistance, and in deploying the assistance in the field.

One of the means of reducing dependency on EEA is to strengthen disaster risk reduction (DRR). It is expected that DRR will provide climate security benefits mainly through contributing to resilience to shocks, and by positively affecting the physical, environmental, social, and economic assets that communities depend upon for their well-being. Relief and rehabilitation are important areas of DRR and have been traditional areas of operation for governments for centuries. As a result, governments have made significant progress in perfecting relief operations in the aftermath of natural disasters, especially for "normal" events (those that are within the experience domain of local stakeholders).

However, extreme events, such as those with a return period of 50 or 100 years or more, are still a challenge for governments especially when they occur at a place and time that is least expected. This is largely due to a lack of experience and expertise in dealing with extreme events, and a lack of capacity, especially at the local level. As a result, many governments require external support for rescue and relief in the short term and for reconstruction and rehabilitation in the long term.

\subsection{Current Status of External Emergency Assistance: A Case of Japan}

Japan contributes a significant amount of EEA to countries affected by severe disasters. Currently, a major proportion of Japan's EEA is allocated to address emergencies emanating from climatic hazards such as floods and typhoons which are also likely to be influenced by climate change in the future (Figure 1).

Climate change projections indicate that losses associated with cyclones will increase, there is likely to be an increase in the average maximum wind speed of cyclones, and flood losses in many locations will increase in the future (high agreement; IPCC, 2012). This indicates the possibility that developed countries like Japan may have to allocate more resources for EEA if the capacity of vulnerable countries is not significantly improved in the future. This could have climate security implications for both donor and recipient countries.

As such, Japan's climate security is affected by a set of complex factors. For example, one of the major sources of climate threat to Japan is related to its food imports. Japan imports more freshwater than the water withdrawn within its borders and saves nearly $20 \mathrm{~km}^{3}$ of water by importing food. Climate change impacts in exporting countries will result in food and water insecurity for Japan (Inuzuka et al., 2008).

Disasters elsewhere can have a significant impact on Japan's economy. For example, the Bangkok floods of 2011 caused a total estimated loss of $\$ 47$ billion, with $90 \%$ of the losses accrued by Japanese companies and related investments (Prabhakar \& Shaw, 2020). This indicates how the impacts of extreme weather events are increasingly becoming transboundary.

Japan invests significantly in developing countries that are highly vulnerable to natural hazards and related losses. Japan's foreign direct investment outflows to Asian countries have been increasing over the past decade. Foreign direct investment has increased especially in Thailand after a brief decline following the 2011 floods. Japanese companies are projected to increase 


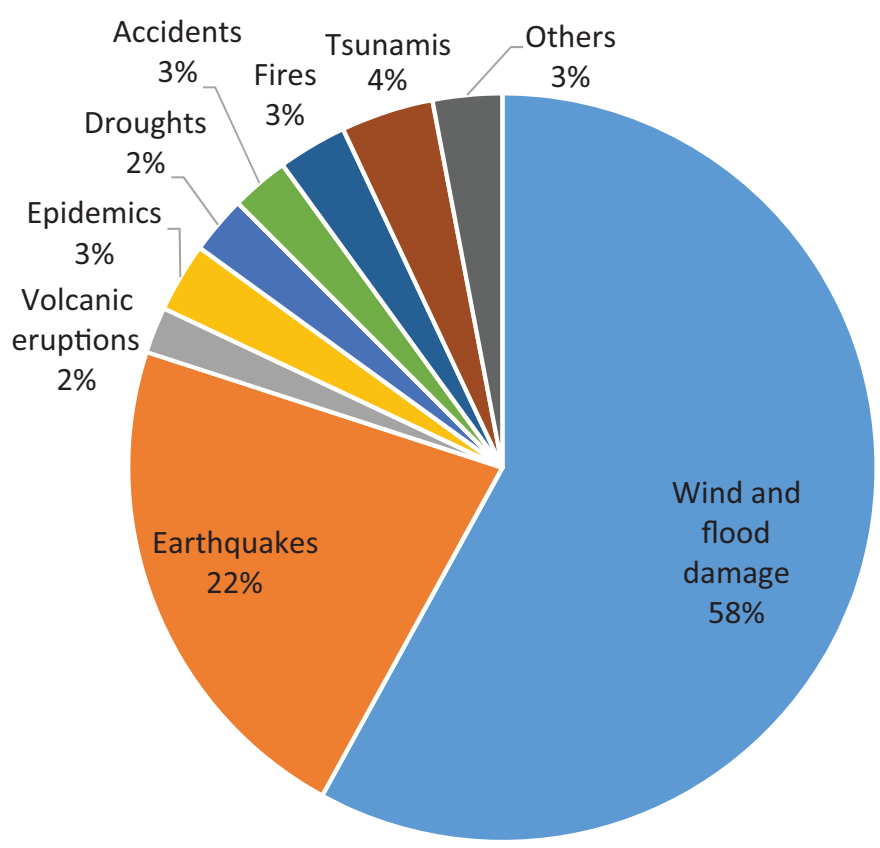

Figure 1. The proportion of EEA provided by Japan by type of events. Source: Japan International Cooperation Agency (JICA, 2017b).

investments in ASEAN (Association of Southeast Asian Nations) and China (JETRO, 2018). This signifies the need for Japan to reconsider and redesign its EEA strategy, thereby maximizing its climate security as well as that of recipient countries.

Japan's first experience with EEA was to respond to the Cambodian refugee crisis in 1979. This issue made the Japanese government realize the necessity of building capacity to send EEA to countries that needed assistance (Kawakami et al., 2014). Following the establishment of the Japan Medical Team for Disaster Relief in 1982, Japan enacted the Law Concerning Dispatch of the Japan Disaster Relief Team (JDR law) in 1987, which expanded the limited scope of Japan's EEA to include medical teams to deal with various significant disasters in general (Ministry of Foreign Affairs [MOFA], 2017). When Japan enacted the Act on Cooperation with UN Peacekeeping Operations and Other Operations in 1992, which deals with conflict-related issues, the area covered by the JDR law was further specified to include natural hazards and human-induced disasters (Nakauchi, 2011). Japan's efforts on EEA consist of three pillars: personnel contribution, in-kind contribution, and financial contribution (MOFA, 2021). Japan International Cooperation Agency (JICA) is in charge of the operation of two of the pillars: (1) personnel contribution, namely dispatching the Japan Disaster Relief Team, and (2) in-kind contribution, namely provision of emergency relief goods. The other pillar, financial contribution, is operated by the Ministry of Foreign Affairs (MOFA), either bilaterally or multilaterally. In the event of a large-scale disaster, Japan provides EEA based upon a request from the government of the country affected (JICA, 2017a).
Focusing on personnel contribution, Japan's EEA consists of five categories: (1) search and rescue team, (2) medical team, (3) infectious diseases response team, (4) expert team, and (5) self-defense force unit (JICA, 2020). Since the implementation of the JDR law in 1987, as of July 2021, a total of 160 teams have been dispatched to 48 countries and regions. Historically, Japan has developed its institutional framework for EEA to meet the needs of countries that have been hit by natural disasters promptly and effectively. There are two major developments worth highlighting concerning operations and the institutional structure of personnel contribution. First was the experience of EEA responding to an earthquake disaster in Central Java, the Republic of Indonesia in 2006. This marked the first time that Japan's EEA included a team to support not just emergency assistance, but also the post-disaster recovery phase (MOFA, 2006). The team reviewed the situation and developed plans for early recovery, thereby making assistance and recovery a seamless, holistic project. Second, in response to the Ebola outbreak in 2015, the newest team out of the five categories, namely the infectious diseases response team, was established (MOFA, 2016). Through operations over 30 years, Japan's EEA has improved in many respects, especially in terms of its effectiveness and flexibility. The other key achievement is its international recognition. In 2010, the search and rescue team was classified as "heavy" by INSARAG (International Search and Rescue Advisory Group) External Classification, which is the highest classification (JICA, 2017a).

While Japan has a significant record of operations since the formal inception of EEA in 1987, there are 
only limited academic reviews that analyze the effectiveness, advantages, or shortcomings of this assistance. This article is an effort to fill this gap, aiming to make the function of EEA more effective, especially with regard to DRR and future risks. Generally speaking, the majority of the reviews and evaluations of Japan's EEA discuss how to strengthen the activities of the Japan Disaster Relief Team, given the legal and institutional framework. There has been research on how to realize effective management of Japan's self-defense force for EEA (Kiba \& Yasutomi, 2014). Issues surrounding the legal or institutional frameworks are also related to the effectiveness of EEA. A typical example is the case of Haiti in 2010. The recipient government was slow to issue a demand for assistance, resulting in a delay in dispatching Japan's Disaster Relief Team. Consequently, there was a discussion on how strictly Japan should adhere to the principle that, as stipulated in JDR law, the country can only dispatch EEA after it receives a request for assistance (Kamata, 2012). Other issues include how to realize efficient logistics or better coordination with the recipient and other donor organizations, and how to manage the health of disaster relief workers (Nakauchi, 2011; Noguchi et al., 2018). Moreover, JICA's review of its own dispatch experience and its research projects to strengthen the activities of EEA are more focused on the efficiency of its operations.

In light of the review of the historical development of Japan's EEA and related literature, there are two areas where significant improvements can be expected in terms of policies and operations for EEA. First, there is a lack of clarity on how to effectively situate EEA in the overall framework of JICA's policy on official development assistance (ODA) which aims to mainstream disarmament, demobilization, and reintegration (DDR) in development or in MOFA's policy on humanitarian aid in general. While JICA's policy on DRR has been in place since 2006 and aims at mainstreaming DRR in development (JICA, 2017b), it is not clear whether this overall framework applies to EEA operations in any sense. A review of reports by JICA for the historical timeline of dispatches of EEA shows that there has been no such consideration of either short-term or long-term perspectives. Similarly, MOFA's policy provides an overall framework for Japan's humanitarian aid policy (MOFA, 2011). After pointing out that human security constitutes the overarching challenge for humanitarian assistance, the MOFA policy discusses the diversification of humanitarian crises. The document encompasses not only natural and human-induced disasters but also includes conflicts and provides general five policy responses: (1) assistance to refugees and internally displaced persons, (2) smooth transition from emergency assistance to early reconstruction and development assistance, (3) response to natural disasters, (4) security of humanitarian aid workers, and (5) civil-military coordination. Concerning natural disasters, the policy underlines that Japan provides wide-ranging support to enhance the capacity of developing countries in their efforts on disaster reduction.

Second, with the recent movement toward aligning DDR and climate change adaptation, the current discussions on EEA lack perspective on covering long-term disaster risk management. $A$ recent study points out that although preparedness is a key factor in DRR, a substantive amount of ODA has been used for EEA, indicating the disconnection between EEA and long-term disaster risk management (Shimano et al., 2016). This aspect of financial issues between overall DRR policies and EEA has been the topic of discussions on development studies concerning ODA in general (Raschky \& Schwindt, 2012; Thérien \& Lloyd, 2000). Beyond the issue of finance, there are significant limitations on establishing a framework for long-term disaster risk management, keeping EEA within the scope of other ODA policies on DDR and climate change adaptation. This issue is reflected in the assessment of the EEA strategy for individual cases.

\subsection{Climate Security, Fragility, and External Emergency Assistance}

To improve the efficacy of various forms of EEA that Japan and other donor countries provide, it is important to assess their effectiveness in both the short and long term. From the short-term point of view, this type of assistance should reach those in need in a timely manner so as to safeguard the life, health, and dignity of the affected people. Further, short-term positive impacts could lead to a long-term engagement between the recipient and donor countries to ensure positive, long-term risk reduction. In addition, such engagements may also spill over into feedback for Japan itself in terms of a positive impact on its economy and people. Hence, such assistance can lead to the long-term outcome of engagements facilitated by short-term opportunities created by extreme events. Here, the concept of climate security and fragility comes in handy when looking at EEA through a new lens, as these concepts provide a long-term perspective on the sustainability of assistance interventions.

Security refers to the political, institutional, and social environment where individuals, societies, and countries have the freedom to decide their current and future wellbeing. Climate security denotes the threats posed by climate change to various aspects of human security (Prabhakar \& Shaw, 2021). It has become evident that climate security is an important issue for both recipient and donor countries. Due to the inclusive nature of what defines climate security, discussions on climate change have been able to expand beyond traditional notions of specific areas such as food and energy security, to encompass a much more holistic meaning.

Climate security can be seen both as a framework that guides policy interventions and institutions, and as an outcome of policies and institutional actions (Figure 2). As can be seen from Figure 2, as a guiding framework for policies, climate security enables integrated response 


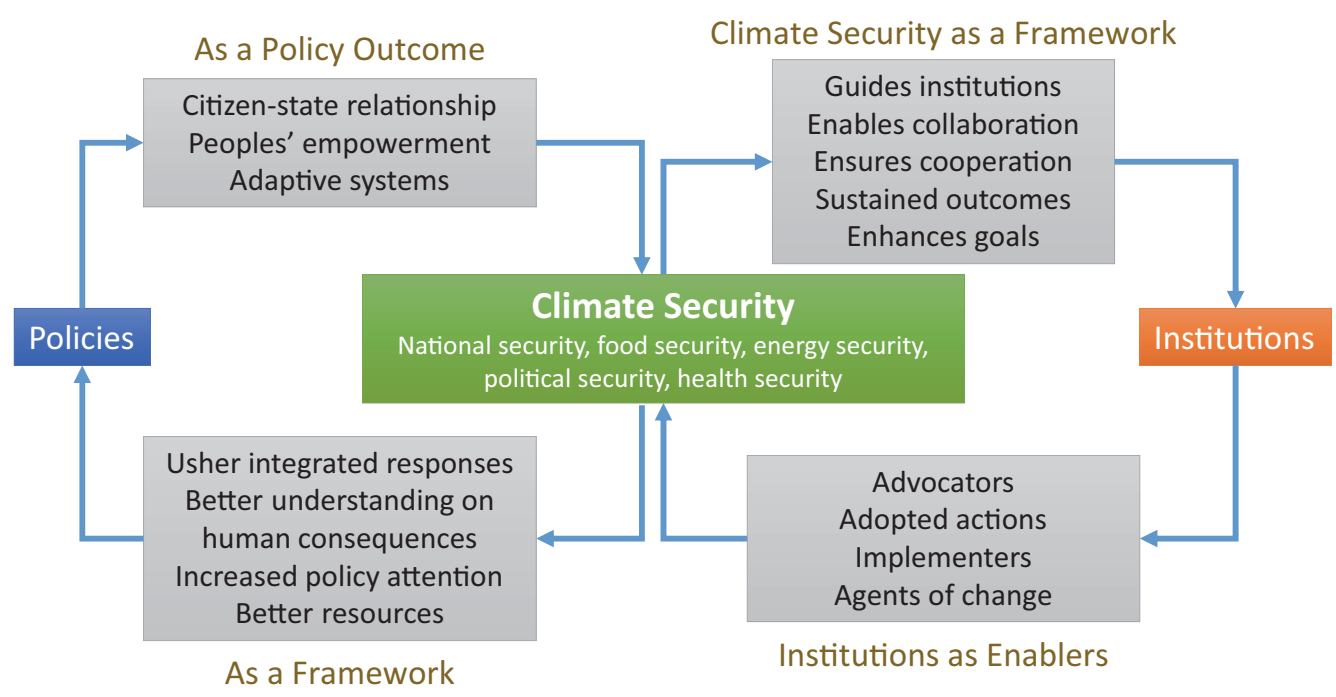

Figure 2. Climate security as a policy outcome and as a framework that guides policies and institutions. Source: Based on Prabhakar and Shaw (2021).

by various actors, helps provide a better understanding of the human consequences of climate change, resulting in better policy attention, and enables dedicated delivery of resources to the causes of climate change. On the other hand, as a policy outcome, climate security bonds together the citizen-state relationship, thus empowering stakeholders and helping to build adaptive systems. Similarly, as a guiding framework for institutions, climate security enables institutions to collaborate, ensures cooperation, sustains the outcome of institutional actions including through collaboration and cooperation, and helps motivate institutional goals and ambitions to strive for better outcomes. These positive impacts on institutions turns them into agents of change with positive overall climate security outcomes in society.

Climate security can manifest in a variety of ways depending on a country's disposition. It is also becoming apparent that climate security is highly interdependent in an increasingly integrated world. Consequently, Japan's climate security can be understood as a function of all the internal and external stresses resulting from climatic events.

Climate fragility has been defined as:

The state of the country's capacity, legitimacy and authority level of the country's government wherein the state is not in a position to offer basic governance functions, lacks ability to develop a mutually constructive relationship with the society and lacks ability to provide basic security to its citizens and institutions. (Prabhakar \& Shaw, 2019, p. 4; see also Ruttinger et al., 2015)

State fragility can be affected by many factors and it has been realized that climate change can act as a threat multiplier for state fragility. Factors such as food price fluctuations, migration and internal displacement, extreme weather events, and unintended impacts of poli- cies can exacerbate state fragility (Prabhakar et al., 2017; Ruttinger et al., 2015). This close connection between climate security and state fragility affects the ability of countries to address the consequences of extreme disasters. For this reason, there is a need to look into the relationship between state fragility and the ability of countries to provide disaster assistance.

Given the above viewpoint, our hypothesis is that the climate fragility risk of countries can provide a good reflection of a country's dependency on EEA. This means that countries that have high climate fragility are characterized by low climate security and high dependency on EEA. Countries with high climate fragility may fail to make maximum use of the EEA they receive as their governance systems are not able to carry out proper EEA management.

\section{Methodology}

\subsection{Development of Climate Fragility Risk Index}

In this article, CFRI was developed as a means of quantifying the climate fragility of countries. CFRI is a unitless index, developed using indicators that directly affect the fragility of states and institutions. The index shows the relative climate fragility of countries. The purpose of CFRI is also to see if state fragility has any impact on the state's ability to provide effective relief assistance to affected people.

At this point, it is important to understand the difference between CFRI and various other risk indices that have been presented prominently in the existing literature. These include, but are not limited to, the Global Climate Risk Index (GCRI) of Germanwatch (Germanwatch, 2021), UNEP's Disaster Risk Index (DRI; UNEP, 2003), and more prominently the Notre Dame Global Adaptation Index (ND-GAIN; Chen et al., 2015). Although there are some overlaps among these indices, the purpose and output of these indices are different and 
have been adopted to varying degrees. Table 1 captures some characteristics of these indices. The final column identifies whether these indices can provide an understanding of the fragility condition of states (which is the purpose of CFRI).

Based upon the realization that the available indices do not adequately provide an understanding of the fragility of a country or an administrative region, a need was identified to develop a CFRI. The conceptual framework (see Figure 3) for developing this index is derived from Prabhakar and Shaw (2019), Prabhakar et al. (2017), and Ruttinger et al. (2015). These studies identified various underlying factors of climate fragility risks such as hazards, migration, food prices, policy and governance, and resource scarcity. The risk-compounding conceptual framework suggests that the capacity of the state and civil society to address risks is negatively affected by a set of climate fragility risks that vary from context to context. These fragility risks tend to be compounded due to the interlinkages that operate among the underlying factors of these risks. The compounding of risks diminishes the capacity of the state to provide necessary services, and further exacerbates the climate change impacts over time if the underlying fragility risks are not addressed and mitigated. With every iteration of this cycle, one can observe a risk magnification as the available capacity is insufficient to mitigate risks in each cycle. For states to reduce climate risks, they need to reverse this cycle by working on the capacity of the state and civil society, and by addressing the underlying factors and decoupling linkages between them so that the compound fragility risks can be mitigated.

A literature review was conducted to identify appropriate indicators for inclusion in the CFRI. Further, these

Table 1. Some prominent risk indices available in existing literature and their ability to assess the fragility nature of states.

\begin{tabular}{lll}
\hline Risk index & Characteristic & Applicability to fragility status \\
\hline GCRI & $\begin{array}{l}\text { An index was developed based on the number of } \\
\text { deaths, deaths per 100,000 population, economic } \\
\text { losses, and loss per unit GDP. The index is based } \\
\text { on the actual disaster impacts in a particular year. } \\
\text { Received prominence. }\end{array}$ & $\begin{array}{l}\text { Doesn't indicate if the state became fragile, doesn't } \\
\text { include any policy and governance-related } \\
\text { indicators. }\end{array}$ \\
& $\begin{array}{l}\text { Unlike GCRI, DRI is robust as it utilizes several } \\
\text { spatial and temporal, risk, and vulnerability } \\
\text { indicators. It helps calculation of the average risk } \\
\text { of death. Not specific to climate change but covers } \\
\text { earthquakes, floods, and cyclones. }\end{array}$ & $\begin{array}{l}\text { Though some indicators include political and social } \\
\text { indicators, the output of the index itself doesn't } \\
\text { indicate whether the fragility state of a country will } \\
\text { be affected. }\end{array}$ \\
& $\begin{array}{l}\text { ND-GAIN employs nearly 74 variables to form } \\
\text { 45 indicators for calculating the vulnerability and } \\
\text { readiness of countries to climate change. }\end{array}$ & $\begin{array}{l}\text { This is the closest index that can indicate the fragility } \\
\text { state of a country as represented by the readiness } \\
\text { component of the index. However, it is complex and } \\
\text { difficult to apply at the sub-national level. }\end{array}$ \\
\hline
\end{tabular}

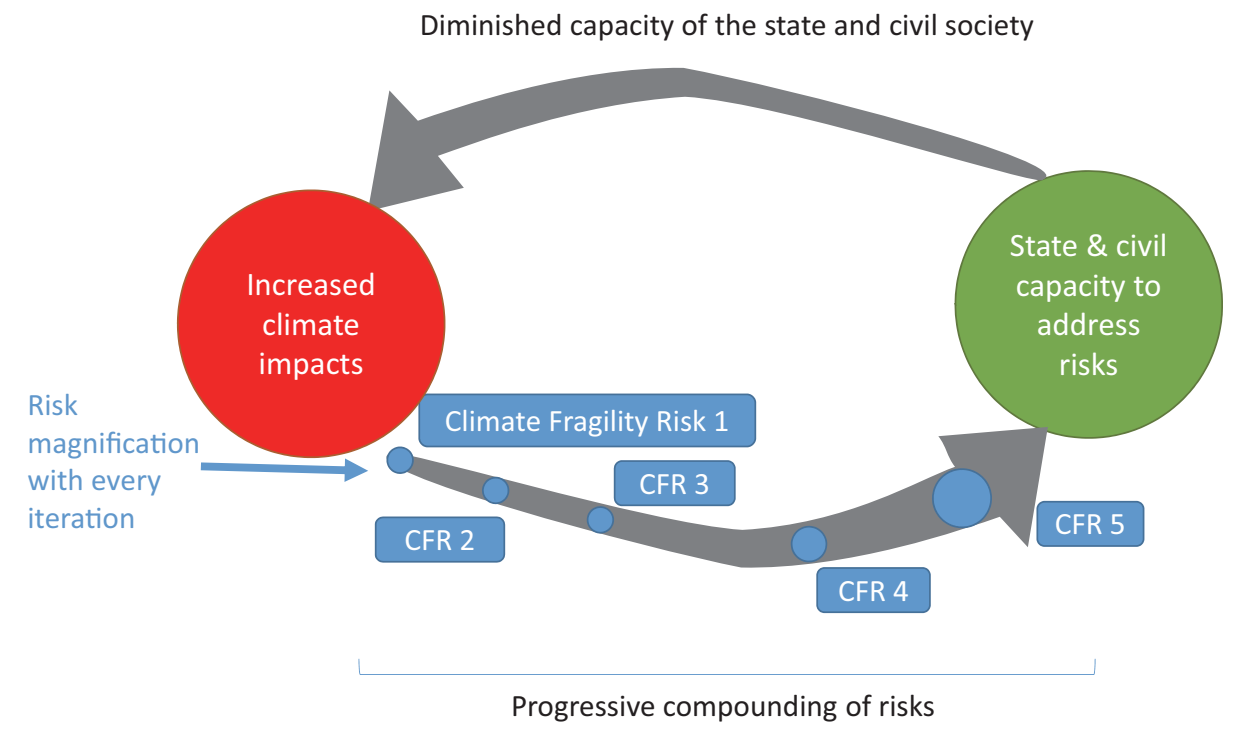

Figure 3. Framework showing compounding of risks and risk magnification. 
indicators were strengthened by the responses provided by experts in an online survey and expert consultations organized as a part of this study. The index was developed using data from sources presented in Table 2. Since data for all indicators are not available, wherever appropriate, a proxy indicator was used as shown in the table.

Data on all the indicators are in different units. This disparity was removed by transforming the data using the linear normalization technique with adjusted saturation levels. Wherever published saturation levels are not available, the saturation levels are adjusted in full. Wherever a range of values are available, the minimum and maximum values were decided accordingly (e.g., as in the case of the Climate Risk Index [Germanwatch, 2019]). No weights were assigned to these indicators in the final CFRI value to avoid the subjective weights that differ from one expert to another. The results are shown as a heat map using the web-based choropleth tool, Carto (Carto, 2019).

\subsection{Developing Critical Threshold Levels for Receiving External Emergency Assistance}

This is a new idea that has been developed by the authors of this article with no known precedence in the existing literature. The basic assumption of the critical threshold levels for EEA is that countries tend to need EEA when disaster damages cross certain critical levels of damages, including loss of life and economic damage, exceeding the needed capacity to manage the emergency. Disaster damage tends to vary even within a country due to varying levels of intensity of disasters, location of the disaster (e.g., highly developed urban areas vs. poorly developed rural areas with different disaster management and mitigation capacities), and the timing of the disaster (e.g., more recent disasters of the same magnitude may cause less damage as governments are continually improving the disaster risk mitigation efforts). Hence, making sense out of this complexity is crucial to understand under what circumstances a country may need EEA so that the assistance providers can be vigilant and provide appropriate assistance (amount and nature) quickly.

The critical threshold concept determines EEA as a function of damage threshold, economic capacity, institutional capacity and so on, as Equation 1 represents:

Equation 1: Country assistance requirement $=f(\theta d$, GDP, financial capacity, institutional capacity...)

In the above equation, $\theta d$ denotes the disaster threshold at which the country tends to depend on EEA.

Table 2. Indicator framework used in developing the CFRI.

\begin{tabular}{llll}
\hline Indicator & Proxy indicator & Rationale and limitations & Source of the data \\
\hline $\begin{array}{lll}\text { Local competition } \\
\text { for water }\end{array}$ & Baseline water stress & $\begin{array}{l}\text { Higher water stress can lead to high competition } \\
\text { for water. However, water may not always be the }\end{array}$ & WRI, 2018 \\
& & $\begin{array}{l}\text { case depending on the local governance as } \\
\text { represented by the governance indicator below. }\end{array}$
\end{tabular}

Extreme weather Climate risk index events

Migration and internal displacement

Food price volatility

Sea level rise (SLR)

Unintended effects of policies

Insured losses affected by migration and internal displacement affected by SLR

World Bank indicator

Insurance claims
$\%$ of the population It covers climatic hazards. It is regularly updated on an annual basis.

Provides information on the internally displaced and migrants. This data was converted into $\%$ of the population.

Calculated as a standard deviation of crop prices over ten years in the local currency.

$\%$ of the population Regulatory Quality
Instead of SLR alone, \% of the population affected by SLR was used to reflect better on the social and economic impacts.

The closest available data on unintended effects of policies is the World Bank Regulatory Quality indicator. It reflects policy effectiveness. We assumed that the higher the regulatory quality, the fewer unintended effects of policies. This mostly doesn't represent losses from
Germanwatch, 2017

IDMC, 2018

FAO, 2018

Climate Central, 2015

The World Bank, 2018

Various sources political and social unrest.

Source: Based on Prabhakar et al., 2017; Prabhakar and Shaw (2019). 
Since various factors can affect the critical thresholds for receiving EEA, an extensive literature review was conducted to identify an exhaustive list of indicators (see the Supplementary File). More than 100 indicators were identified grouped into four categories. These categories are a) disaster impact characteristics, b) national response capacity, c) international response capacity, and d) disaster exposure, vulnerability, and capacity. A select few indicators are presented in the Supplementary File attached to this article.

For developing this critical threshold, data from openly available databases such as EM-DAT and UN OCHA was used. Following consultations with these data sources and with national-level disaster management officers and databases, the study team realized that there were pertinent data gaps to developing a critical threshold measurement using this exhaustive list of indicators. A decision was made to restrict the number of indicators to only a few, including EEA received in monetary terms (USD) as a dependent variable. The independent variables selected include deaths, number of people affected, damage, GDP, governance effectiveness, and poverty. These indicators were qualitatively narrowed down after assessing their interdependency with other indicators listed in the Supplementary File and depending on the data availability. The study team realized that the lack of data has critically restricted the range of indicators to be included in the critical threshold analysis.

The economic impact of extreme events is an important consideration that determines the need for EEA. Hence, the reason for using GDP, a macroeconomic indicator, and poverty, another economic indicator of people's income, has been that GDP indicates the overall country's economic capacity to withstand economic shocks from extreme events, while the poverty headcount ratio indicates the proportion of people that may require immediate economic relief. These variables were in turn assessed through Principal Component Analysis (PCA) using the Oblimin rotation (assumption: Principal components [PCs]/factors are correlated), and the factor number was reduced based on the rule of Eigenvalue $<1$. The PCA helped group these independent variables into a few groups.

\subsection{Expert Consultations for Understanding the Effectiveness of External Emergency Assistance}

The author team organized two policy consultation workshops in Manila, the Philippines, and Dubai, United Arab Emirates, for stakeholders from Pakistan to understand, firstly, how EEA provided by countries like Japan was effective in managing the disaster emergencies, and then how to improve the efficacy of EEA in the future, especially by keeping in view the climate security of both the donor and recipient countries. These workshops brought together various relevant stakeholders involved in overseas development assistance, emergency relief assistance, long-term rehabilitation and risk reduction, and climate security. The experts were drawn from various government departments, academia, the research community, NGOs, and civil society engaged in the field of disaster risk management. These consultations have helped to develop a common understanding of the current issues with emergency relief assistance and other related development assistance programs, and to identify means to improve them in such a way that both the recipient and donor country enjoy positive benefits. Discussions at these workshops have contributed to a deeper understanding of the opportunities and challenges for developing the critical threshold concept (Section 4.2) and other means of improving EEA effectiveness (Sections 4.3 and 4.4 ) presented in this article.

\section{Results and Discussion}

This section discusses the results of the CFRI and presents various ideas on how to improve EEA. These discussions are drawn based on the authors' expert judgement of the current state of affairs for EEA as well as a series of consultations that the authors have conducted.

\subsection{Climate Fragility Risk Index}

The CFRI investigation revealed that the amount and form of climate fragility risks vary by country (Figure 4). This emphasizes the importance of developing countryspecific strategies for addressing climate fragility risks. It also emphasizes that the ability of countries to respond to climate extremes can vary due to different underlying fragility risks. The average CFRI for developing countries, which include Bangladesh, Cambodia, China, India, Indonesia, Lao PDR, Malaysia, Myanmar, Pakistan, and the Philippines was 0.76. For developed countries, comprising Australia, Japan, and the Republic of Korea, the CFRI was 0.66 , showing a marginally lower CFRI than developing countries.

Variances in exposure to sea-level rise (where Vietnam and Thailand are particularly susceptible) and food price volatility accounted for the majority of the differences between countries (where Pakistan scored highest). When it came to metrics of internal displacement and the regulatory quality of country governance systems, there was much less variation. Because of its high sensitivity to water stress and high food price volatility, Australia had a comparatively high CFRI among developed countries.

Furthermore, the investigation revealed a reasonably close relationship between CFRI and country GDP per capita. The analysis demonstrated a link between a country's developmental condition and its climate fragility. This indicates that a country's developmental status has a direct impact on the severity of how risks can compound and magnify quickly (as interpreted through the framework in Figure 3).

The power relationship between CFRI and GDP appears to point to a key level of per capita income 


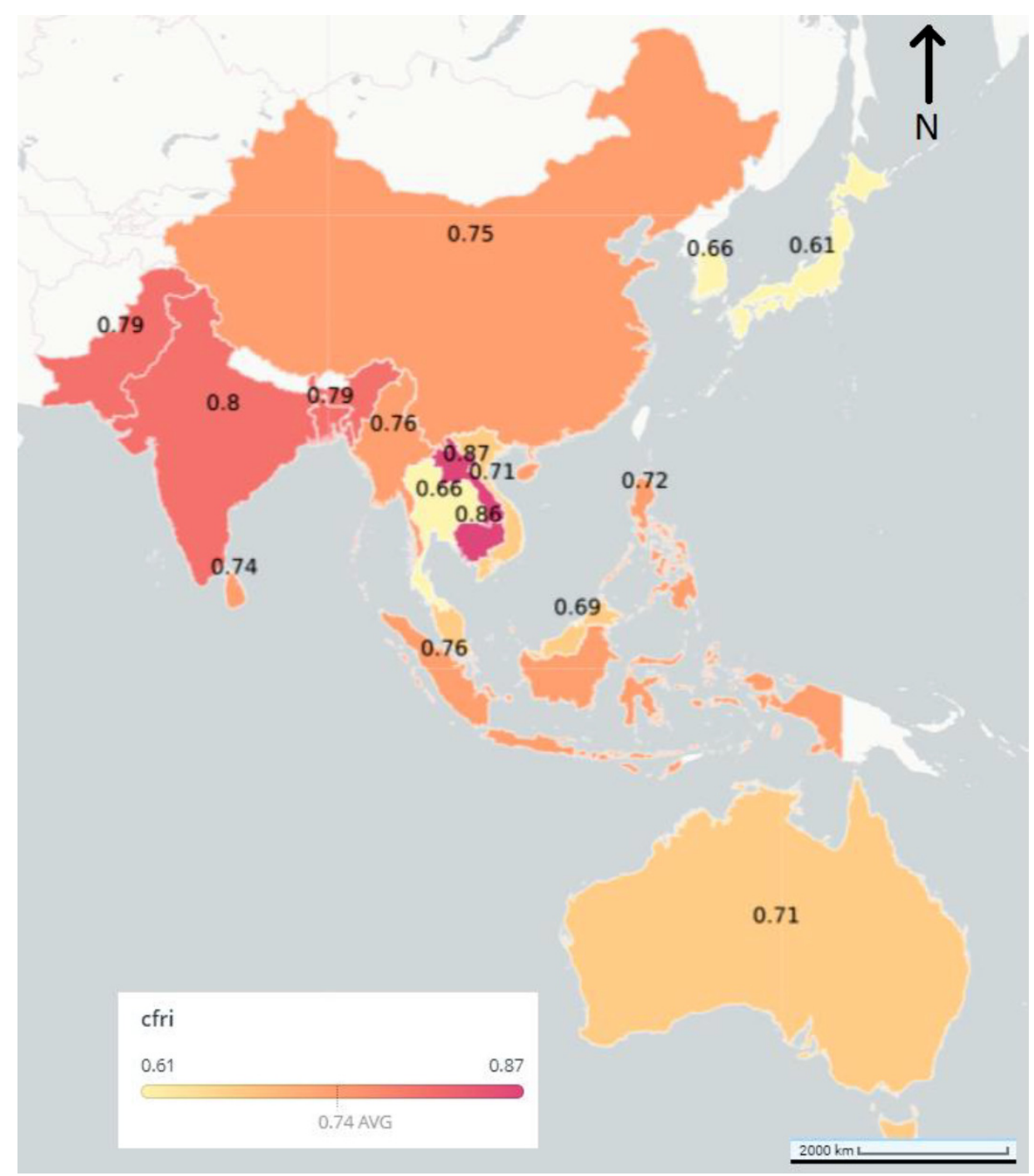

Figure 4. CFRI of countries in Asia and Oceania.

below which countries are more vulnerable to climate change. With the inclusion of more developed countries in the analysis, the association between CFRI and per capita GDP became stronger (Figure 5). The relationship between a country's development status and climatic concerns has long been acknowledged in the literature (Hallegatte, 2013).

The CFRI could provide a yardstick to measure the relationship with a country's ability to provide relief in the aftermath of disasters. It helped to identify the relationship between the climate fragility of states and with the developmental state of the countries. Largely, countries that are economically developed may suffer relatively less from fragility risks. However, climate fragility is still a major concern for both developed countries and developing countries, albeit to a different degree. Furthermore, developing the critical threshold concept will identify critical data gaps that the national governments will have to address in the future, as well as identifying innovative means of obtaining the information, for example through crowdsourcing or employing remote sensing technologies for damage assessment. This would entail bringing together the science and technology ministries and other relevant stakeholders to engage with the DRR community at the national level to develop an information platform that helps in the quick assessment of disaster impacts.

\subsection{Critical Threshold Concept for the Emergency Relief Readiness}

The critical threshold analysis indicated that countries have different critical thresholds for EEA. The PCA has helped to reduce the factors down to two PCs. After conducting the PCA, a regression equation for EEA dependence was developed with two PCs. The following are the critical thresholds of EEA for selected countries:

$$
\begin{aligned}
& \text { Afghanistan }=-0.007 \times \text { PC1 }-25555 \times P C 2+38020265 \\
& \text { Bangladesh }=0.000 \times P C 1+7.058 \times P C 2+19520455 \\
& \text { China }=0.008 \times P C 1-2.50 \times P C 2+20740127
\end{aligned}
$$




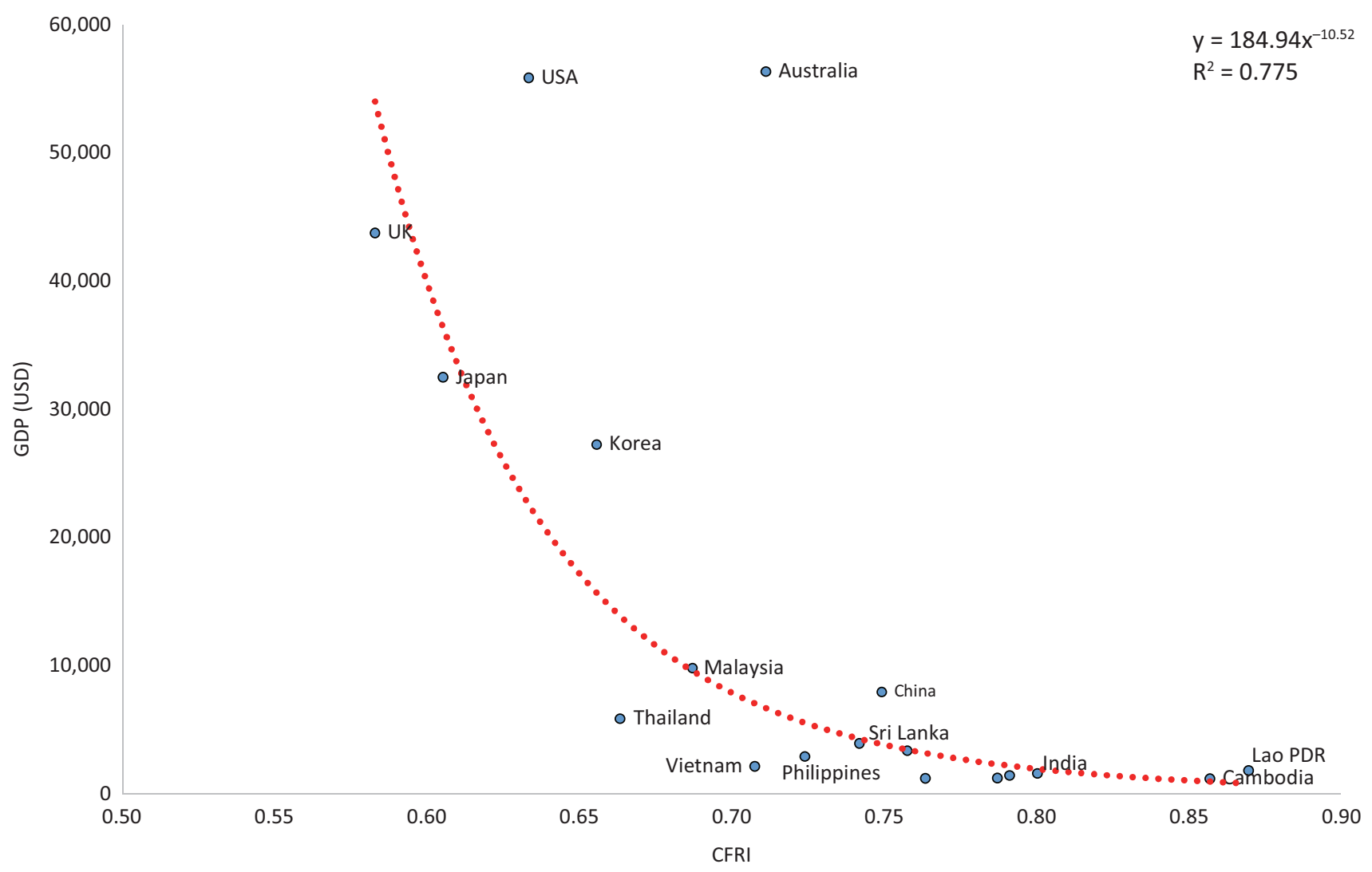

Figure 5. The GDP and CFRI nexus.

$$
\begin{aligned}
& \text { India }=-8.55 \times \text { PC1 }+0.000 \times \text { PC2 }+38072756 \\
& \text { Indonesia }=4.48 \times \text { PC1 }+50.46 \times \text { PC2 }-9700875 \\
& \text { Pakistan }=0.04 \times \text { PC1 }+112 \times \text { PC2 }-1305814894 \\
& \text { Philippines }=0.948 \times \text { PC1 }-0.002 \times \text { PC2 + 58522475 } \\
& \text { Sri Lanka }=0.001 \times \text { PC1 }+57.2 \times \text { PC2 }-19513408 \\
& \text { Vietnam }=0.000 \times \text { PC1 }+3.421 \times \text { PC2 }-2977399
\end{aligned}
$$

Taking the example of the Philippines, it should be understood that the Philippines tends to call for EEA when the PC1 reaches a value of 58522475 . Here, PC1 is comprised of disaster impact indicators while PC2 consists of macroeconomic capacity. The composition of PCs varies by country as shown in Table 3. The percentage $\sigma^{2}$ in the table indicates the proportion of variance explained by each PC. It can be observed that in most cases, GDP and poverty are the common factors in PC1 while the number of people affected or dead are the most common factors in PC2. This indicates that the country's economic capacity is the most important factor in determining whether or not a country calls for EEA.

It should be understood that disaster management capacity and economic capacities within a country are not uniformly developed. Therefore, whether or not a country needs EEA depends on where the event occurred. For example, in a relatively well-developed economy, an extreme event in a remote and underdevel- oped region could inflict severe damage, requiring significant EEA.

The relation between the country assistance requirement and damage thresholds (disaster impacts) could vary widely among countries. Some countries may follow reliable damage threshold-assistance relationships: e.g., as shown in Figure 6, countries A and B are calling for EEA only after disaster losses cross a certain level every time they called for external assistance (instances marked with circles). It is evident that for these countries, the concept of critical thresholds for assistance works well. However, in other countries this function is less clear, e.g., countries $E$ and $H$ seem to call for EEA across all the damage levels they faced. This could be due to varied capacities in different parts of these countries, or the very low capacity of countries to deal with disaster emergencies in general. In these cases, the application of critical threshold should be further specialized to consider country-specific circumstances, as well as the varied capacities of local governments and institutions within a country. Hence, the research needs to identify a means to reliably estimate assistance thresholds that work for all countries. One approach is to have a high resolution of the threshold, i.e., to have subregional or sub-national thresholds for the assistancedamage functions to work well. At the moment, there is insufficient information to determine these hypotheses, and collecting this data to validate this hypothesis is time-consuming. 
Table 3. Composition of PCs of the critical thresholds for selected countries in Asia.

\begin{tabular}{llclc}
\hline Country & PC1 & $\% \sigma^{2}$ & PC2 & $\% \sigma^{2}$ \\
\hline Afghanistan & GDP, poverty, affected & 42 & Dead, governance & 29 \\
Bangladesh & Poverty, GDP, governance & 50 & Affected, dead & 23 \\
China & Damage, dead, governance & 47 & Poverty, GDP, affected & 26 \\
India & Poverty, GDP, affected, dead & 39 & Damage, governance & 21 \\
Indonesia & GDP, poverty, governance & 59 & Affected, dead & 28 \\
Pakistan & Poverty, governance, GDP, affected & 58 & Dead & 24 \\
Philippines & Dead, damage, affected & 63 & Poverty, governance, GDP \\
Sri Lanka & GDP, poverty & 41 & Dead, affected, governance & 32 \\
Vietnam & Governance, GDP, damage, poverty & 58 & Affected, dead & 26 \\
\hline
\end{tabular}
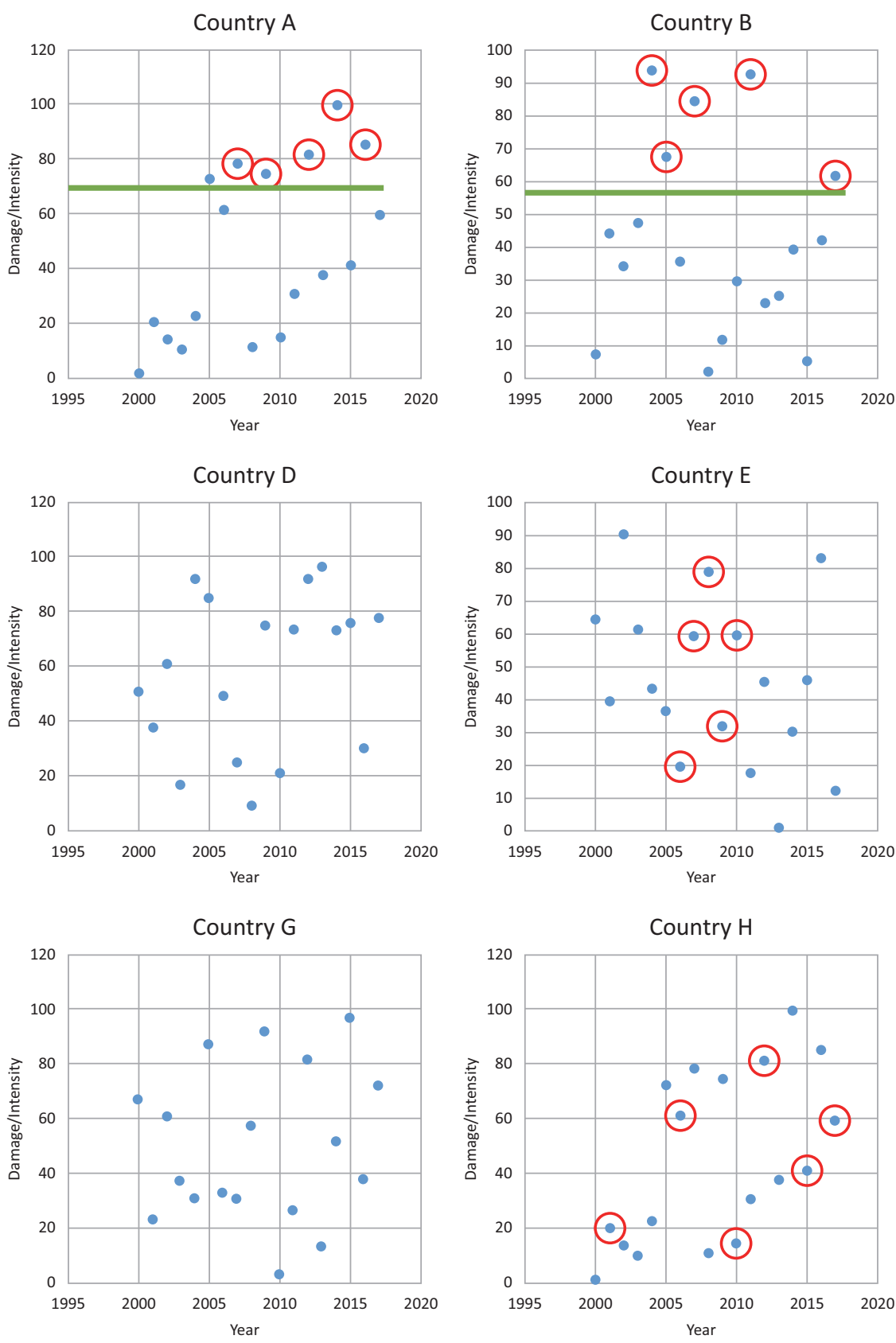
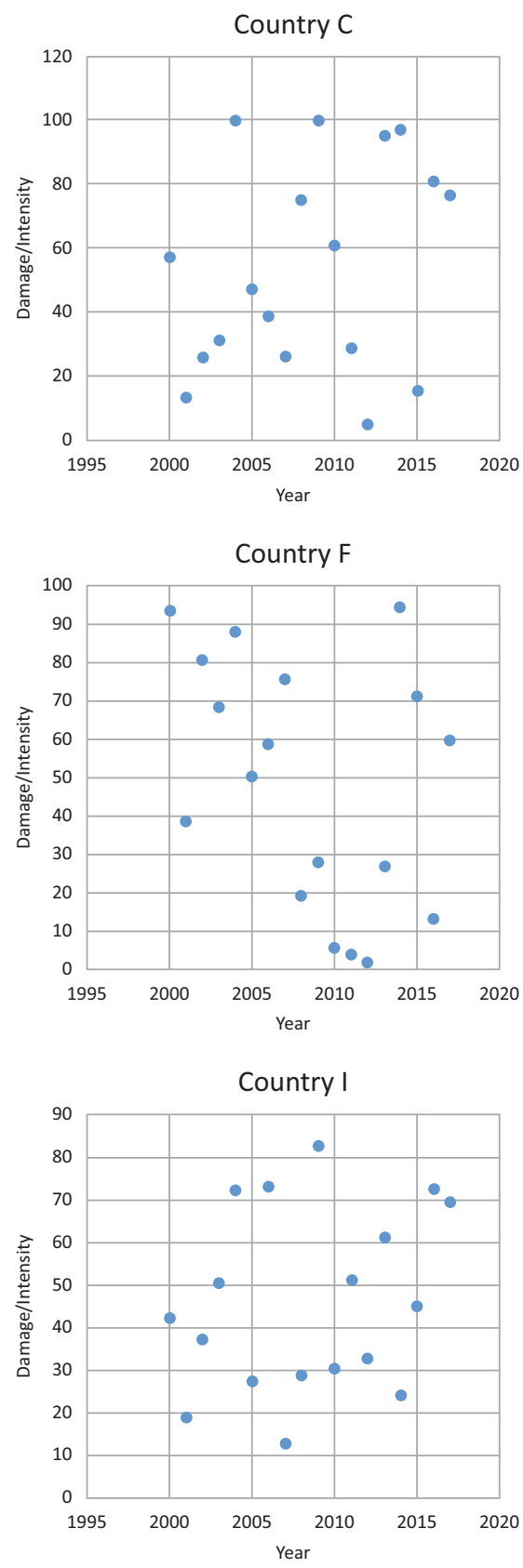

Figure 6. Pictorial depiction of critical threshold concept. Source: Prabhakar et al. (2019). 


\subsection{Delivering Appropriate International Emergency Relief Assistance}

The current picture of how emergency relief is delivered across international borders is rather complex and chaotic, and, over the years, efforts have been made to improve relief delivery across borders in a systematic manner. Efforts on an international level are largely led by UN OCHA wherein it strived to improve prioritization and reduce duplication while ensuring that relief reaches the neediest under diverse circumstances. It does so by engaging with relief coordination and by streamlining procedures for relief finance delivery by sharing information among the participating countries and institutions. Other than UN OCHA, non-governmental agencies such as the International Federation of Red Cross and Red Crescent Societies and Red Cross continuously raise resources for assisting with emergencies. The Red Cross works independently, often providing financial support not to governments and institutions, but rather, directly to those areas and people affected. The Red Cross also works with governments to strengthen their relief coordination mechanisms, by contributing to the development of national-level rules and regulations and carrying out capacity building. Despite these efforts, international emergency relief delivery can still benefit from improvements in the following areas: (1) timely delivery of relief, (2) delivery of appropriate relief, and (3) treating relief and recovery phases in isolation.

\subsubsection{Timely Relief Delivery}

Often, international relief may be delayed due to the time-consuming coordination that has to take place between governments and institutions, and the lack of information on what kind and how much relief is needed. There are instances where the relief continued to arrive even years after the disaster making the relief ineffective for recipients.

\subsubsection{Ensuring Appropriate Relief}

Due to limited time and information available in the immediate aftermath of a disaster requiring international assistance, there are often limitations to relief material arriving in disaster-affected locations. These limitations include: (1) insufficient relief (relief material may not be sufficient in quantity to the affected population),
(2) poor quality relief (poor quality food and other items that are considered unusable and or below the dignity of the affected people), and (3) inappropriate relief (relief material that is not suitable to local conditions, e.g., wool blankets sent to a tropical country).

\subsubsection{Treating Relief as an Isolated Part of the Disaster Risk}

Most of the time, the experiences gained during disaster relief operations can provide deeper insights into disaster risks and vulnerabilities. It is important that messages received during the period of disaster relief are used to inform the risk reduction interventions implemented after the relief phase (Figure 7). However, agencies that engage in disaster relief, mostly at the national level, are often different from the agencies engaged in reconstruction, preparedness, and risk mitigation. As a result, the important messages and lessons learned at the relief stage may be lost and do not contribute to long-term risk reduction. Even though countries are developing unified DRR mechanisms at the national level with coordination in the form of national and local DRR committees, there is still ample evidence from those consultations that the messages from the relief phase are not properly passed on so as to inform the subsequent risk reduction interventions. Moreover, networks and relationships formed during relief do not materialize into long-term engagements for affecting sustained risk reduction, which is a huge lost opportunity for risk reduction.

To address these issues, several interventions have been taken up both at the national level and international levels. For example, UN OCHA strives to communicate with major relief providers to provide appropriate relief and coordinate finances. Similarly, national governments are preparing guidelines to make efficient relief delivery (e.g., the Philippines International Humanitarian Assistance Guidelines). Our consultations indicate that a pre-emptive relief delivery mechanism could help address time delays and delivery of inappropriate relief. For example, the Red Cross is working on the idea of forecast-based relief, whereby relief delivery is preempted based on the forecasted damages at the local level. The consultation processes employed for developing modified Philippines International Humanitarian Assistance Guidelines instilled similar ideas among the relevant government departments in the Philippines. There is a growing emphasis for countries to reduce

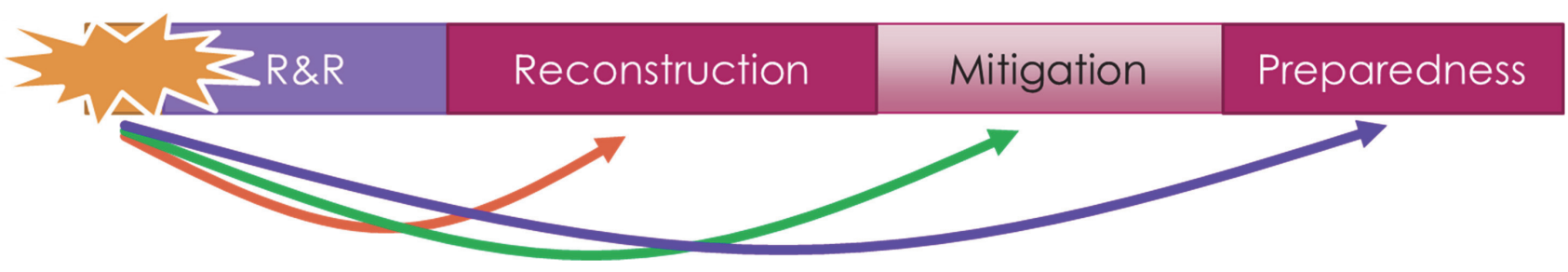

Figure 7. Linking lessons from the relief and rehabilitation stage to the rest of the DRR stages. 
their international relief assistance dependency and for focusing the external relief on niche areas and to link these interventions with the long-term risk reduction measures.

\subsection{Necessary Developments at the National Level}

\subsubsection{Improvements at the National Level}

National disaster risk management committees play a crucial role in recommending the declaration of national calamity in affected countries. For example, in the Philippines, it is the National Disaster Risk Reduction and Management Council that advocates the president to declare a certain disaster as a national calamity, and such a declaration automatically qualifies the government to call for external assistance. In Pakistan, a national calamity is declared by the prime minister with advice from the National Disaster Management Authority. These agencies need sufficient and timely information on the relief needs on the ground on a realtime basis to decide on the need to call for EEA. While the formal process proceeds at its own pace, the proactive international assistance providers often do not wait for the official assistance request but rush the assistance to the affected countries based on the information they have at that time and according to their experience. Hence, properly documenting past assistance experiences and quantifying them in terms of critical needs at each level of disaster is important and should be shared with all donor countries and institutions for appropriate relief delivery.

\subsubsection{Donor Country Policy on External Emergency Assistance}

It is often policy in donor countries that influence the nature and effectiveness of EEA. The policy in Japan on provision of the EEA is that it will only respond to specific official requests made by the affected countries. In fact, there were only very few instances where Japan has sent relief or an assistance team voluntarily without waiting for an official request from the affected country. Japan's stance on external assistance has significant implications for the design and scope of the critical threshold concept since the concept is based on delivering the "appropriate relief at the appropriate time."

Since Japan only responds to specific official requests, depending on the way the emergency assistance requests are made, many issues associated with voluntary relief assistance could be inherently and partially addressed. The critical threshold concept works best for circumstances where the voluntary deployment of assistance is under consideration. Nevertheless, Figure 8 shows the appropriate location where such a framework can be put to operational use within the JapanPhilippines context (highlighted by the red-colored decision box). Here, the donor countries or agencies that provide EEA can refer to the critical threshold values, developed based on either historical data or on projected hazard intensity and magnitude, and then they can decide whether or not the impending disaster is likely to overpower the country's economic capacity to respond or if the country needs external assistance.

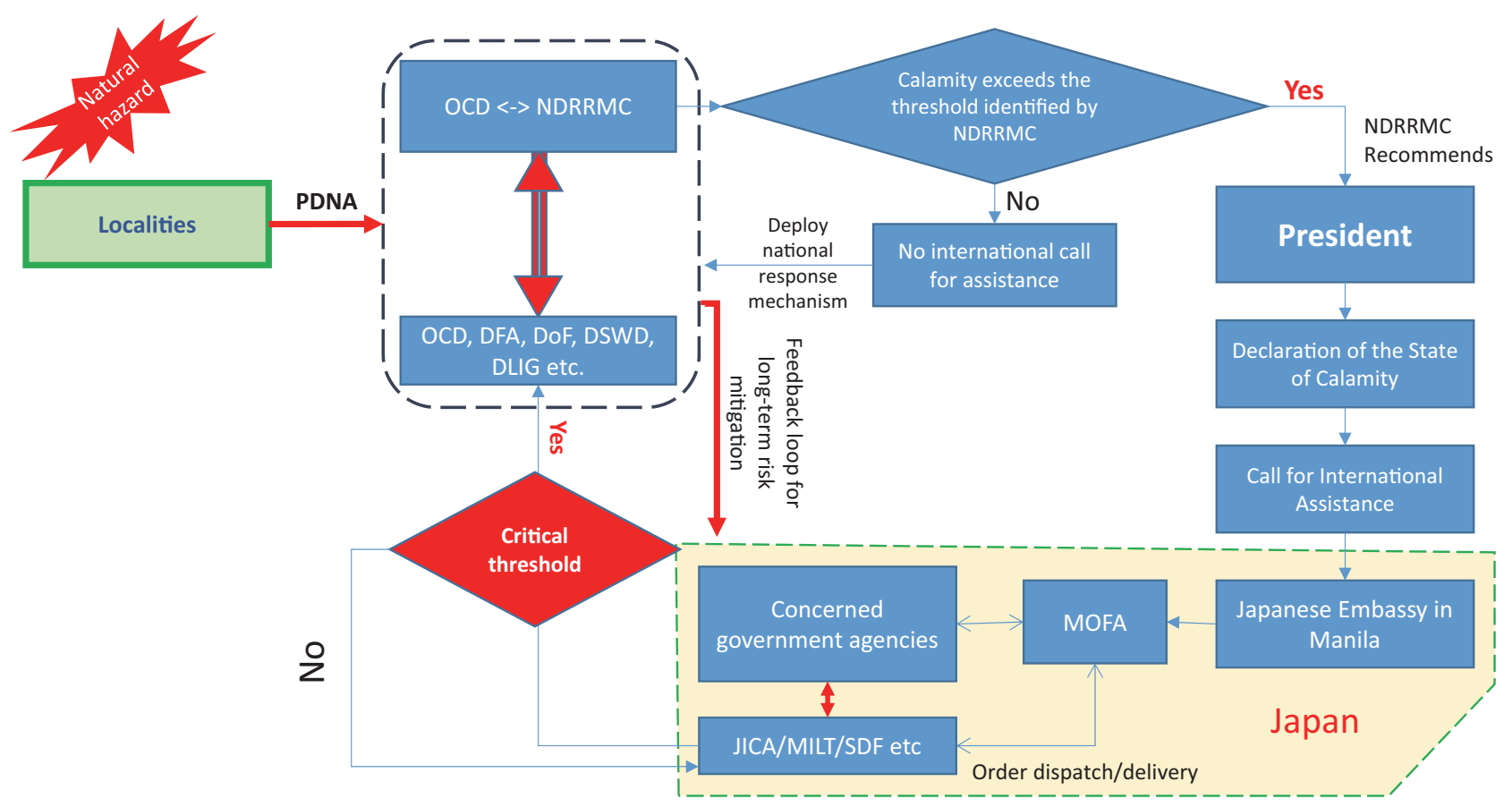

Figure 8. Pictorial representation of the location of critical threshold framework operating in a bi-lateral relief assistance paradigm; in this case, the example is between Japan and the Philippines. Source: Prabhakar et al., 2019. 


\section{Conclusions}

Climate change has significant implications for extreme events and, as a result, will make many vulnerable countries depend on EEA, including in Asia. This is likely to have an impact on both recipient and donor countries. As a major donor in Asia, Japan will be profoundly impacted. To some extent, EEA has costs and benefits for both donor and recipient countries. Hence, any improvements in EEA will benefit both the donor and recipient countries to a varying degree. Future improvements to EEA should be made by keeping the climate security and fragility concepts in mind as they can guide countries to ensure positive and long-term benefits from short-term relief engagements. They can also help countries to minimize dependency on external assistance.

The critical threshold concept can deliver multiple benefits for fine-tuning EEA in the aftermath of extreme events such as typhoons, as there is often very little time for the national governments to evaluate the situation and respond adequately. To address the issue of EEA effectiveness, we have shown how the climate fragility of countries can have an impact on the development status of countries and in turn possibly influence their dependency on EEA. We have also shown the concept of a critical threshold for extreme events and argued that this concept can be employed to pre-empt EEA delivery effectively. However, the use of such tools needs to be implemented without impinging upon national sovereignty, as donor countries have the right to decide how to support the affected countries (i.e., either voluntarily or upon request) and how the EEA recipient countries want to receive assistance (e.g., the nature and amount of assistance).

Whether or not countries such as Japan, which mainly only respond to official requests for EEA by the affected countries rather than responding voluntarily, can utilize the concept of critical threshold remains to be seen. Japan may still be able to use this analysis to strengthen future EEA by looking at the past experiences and find ways to strengthen its response, develop country-specific EEA strategies for maximizing effectiveness, and use future climate projections to understand EEA implications.

During the consultations organized by the authors, it became evident that countries in Asia are in favor of improving their disaster relief assistance mechanisms and are willing to engage with international stakeholders to harmonize measures for delivering focused relief assistance with a long-lasting impact. However, some questions remain which will be important to move forward. For example, it is still not clear how the relief assistance requests are treated by donor countries such as Japan, i.e., what priorities the donor considers before delivering the assistance, what determinants guide the donor to provide external assistance, how a donor consults with other agencies within the donor country, and how the final decision-making is done on what to deliver and how.
Is it always the request of the recipient country that prevails, or do donors consider long-term implications in taking decisions?

There are limitations concerning the development of the critical threshold concept, including limited data availability, fragmented data, i.e., data spread across different ministries and departments, and sensitivity of sharing data with foreign governments especially in terms of the number of military deployed, the location of stock, timeframe for deploying certain types of relief, etc. There is a need to address these issues before coming up with a reliable decision support system for strengthening EEA and eventually minimizing dependency over the medium to long term.

\section{Acknowledgments}

Authors are grateful for the financial support received from the Environment Research and Technology Development Fund (2-1801), Environment Research and Technology Development Fund (2-2102), and Strategic Research Fund (SRF) of the Institute for Global Environmental Strategies.

\section{Conflict of Interests}

The authors declare no conflict of interest.

\section{Supplementary Material}

Supplementary material for this article is available online in the format provided by the author (unedited).

\section{References}

American Security Project. (2012). Climate security report. Carto. (2019). Carto. https://carto.com

Chen, C., Noble, I., Hellman, J., Coffee, J., Murillo, M., \& Chawla, N. (2015). University of Notre Dame global adaptation index. University of Notre Dame.

Climate Central. (2015). Mapping choices: Carbon, climate, and rising seas-Our global legacy.

FAO. (2018). FAOSTAT [Data set]. FAO. http://www.fao. org/faostat/en/\#home

Germanwatch. (2017). Global climate risk index 2018.

Germanwatch. (2019). Global climate risk index 2019.

Germanwatch. (2021). Global climate risk index.

Hallegatte, S. (2013). An exploration of the link between development, economic growth, and natural risk (background paper for the 2014 World Development Report). The World Bank.

IDMC. (2018). Global report on internal displacement.

Inuzuka, T., Nitta, T., Hanasaki, N., Kanae, S., \& Oki, T. (2008). Detailed analysis on the virtual water import to Japan focusing on the origin of water supply. Proceedings of the Hydrolic Engineering, 52(1), 367-372. https://www.jstage.jst.go.jp/article/ prohe1990/52/0/52_0_367/_pdf/-char/en 
IPCC. (2012). Managing the risks of extreme events and disasters to advance climate change adaptation. Cambridge University Press.

Japan International Cooperation Agency. (2017a). Disaster relief and JICA: Striving to make a difference [Brochure]. https://www.jica.go.jp/english/our_ work/types_of_assistance/emergency.html

Japan International Cooperation Agency. (2017b). JICA's cooperation for disaster risk reduction: Disaster resilient society for all [Brochure]. https:// www.jica.go.jp/english/our_work/thematic_issues/ disaster/materials.html

Japan International Cooperation Agency. (2020). Emergency disaster relief. https://www.jica.go.jp/english/ publications/reports/annual/2020/c8h0vm0000fc7 q2b-att/2020_24.pdf

JETRO. (2018). JETRO global trade and investment report 2018-Global economy connected via digitalization.

Kamata, F. (2012). Kokusai kinkyu enjo: Kokusaiteki nettowaaku ni yoru saigai taiou [Recent trends of international disaster relief: Development of international networks]. Reference, 62(4), 5-16. http://ci.nii. ac.jp/naid/40019295434/ja

Kawakami, I., Koizumi, K., Robinson, C., Sato, Y., Takzaa, S., Yamagami, S., \& Yamamoto, S. (2014). $A$ report on the local integration of Indo-Chinese refugees and displaced persons in Japan. UNHCR. https://www.unhcr.org/jp/wp-content/uploads/ sites/34/protect/IndoChineseReport.pdf

Kiba, S., \& Yasutomi, A. (2014). Nihon no kokusai heiwa kyoryoku katsudo ni okeru mingun kyoryoku apurouchi no kadai: Minami suudan kokusai heiwa kyoryoku gyomu to filipin kokusai kinkyuu enjo katsudo kara [Challenges in Japanese approaches to civil-military cooperation: Cases in the International Peace Cooperation Missions in South Sudan and the Philippines]. Journal of International Cooperation Studies, 22(1), 77-108.

Ministry of Foreign Affairs. (2006). Earthquake disaster in Central Java, Republic of Indonesia. https://www. mofa.go.jp/policy/disaster/indonesia-2/index.html

Ministry of Foreign Affairs. (2011). Humanitarian aid policy of Japan. https://www.mofa.go.jp/policy/ emergency/index.html\#ha

Ministry of Foreign Affairs. (2016). Japan's response to the Ebola outbreak in West Africa. https://www. mofa.go.jp/af/af1/page23e_000338.html

Ministry of Foreign Affairs. (2017). White paper on development cooperation 2017. https://www.mofa.go.jp/ policy/oda/page22e_000860.html

Ministry of Foreign Affairs. (2021). Japan's contribution to UN peacekeeping operations. https://www.mofa. go.jp/policy/un/pko/index.html

Nakauchi, Y. (2011). Kokusai kinkyu enjotai no enkaku to konnichi no kadai: Motomerareru daikibo saigai ni taisuru kokusai kyoryoku no suishin [History of international emergency relief teams and today's challenges: Promoting international cooperation for large-scale disasters]. Rippo to Chosa, 323, 3-12.
Noguchi, N., Inoue, S., Shimanoe, C., Akinaga, K., Ueno, M., Takahashi, H., \& Shinchi, K. (2018). Deploymentrelated difficulties of Japanese disaster relief workers by mission duration: A cross-sectional study. Health Emergency and Disaster Nursing , 5(1), 40-47. https://doi.org/10.24298/hedn.2016-0019

Prabhakar, S., \& Shaw, R. (2019). Globalization of local risks through international investments and businesses: A case for risk communication and climate fragility reduction. UNDRR.

Prabhakar, S., \& Shaw, R. (2020). International investments and businesses as enablers of globalization of local risks: A case for risk communication and climate fragility reduction. Progress in Disaster Science, 8, Article 100125. https://doi.org/10.1016/j.pdisas. 2020.100125

Prabhakar, S., \& Shaw, R. (2021). State fragility and human security in Asia in the context of climate and disaster risks. In J. Pulhin, M. Inoue, R. Shaw, J. Pulhin, M. Inoue, \& R. Shaw (Eds.), Climate change, disaster risks and human security: asian experience and perspectives (p. 37-56). Springer.

Prabhakar, S., Shaw, R., Ruttinger, L., \& Mori, H. (2017). Climate-fragility risks in Asia: The development nexus. Institute for Global Environmental Strategies.

Prabhakar, S., Tamura, K., \& Ikeda, M. (2019). Maximizing the climate security benefits of external emergency assistance. Institute for Global Environmental Strategies.

Raschky, P. A., \& Schwindt, M. (2012). On the channel and type of aid: The case of international disaster assistance. European Journal of Political Economy, 28(1), 119-131. https://doi.org/10.1016/j.ejpoleco. 2011.07.001

Ruttinger, L., Smith, D., Stang, G., Tanzler, D., \& Vivekananda, J. (2015). A new climate for peace: Taking action on climate and fragility risks. Adelphi; International Alert; Woodrow Wilson International Center for Scholars.

Shimano, T., Kimura, R., Hayashi, H., Nagatomo, N., \& Sakurada, Y. (2016). Proposal for development cooperation to enhance the capacity on disaster emergency response in developing countries: A case study of curriculum development in the People's Republic of China. Journal of Disaster Research, 11(2), 341-353. https://doi.org/10.20965/jdr.2016.p0341

The World Bank. (2018). DataBank Worldwide Governance Indicators. Databank.

Thérien, J. P., \& Lloyd, C. (2000). Development assistance on the brink. Third World Quarterly, 21(1), 21-38. https://doi.org/10.1080/01436590013206

UNEP. (2003). Global risk and vulnerability index trends per year (GRAVITY).

UN Office for the Coordination of Humanitarian Affairs. (2021). Humanitarian aid contributions [Data set]. Financial Tracking Service.

WRI. (2018). Aqueduct Country and River Basin Rankings [Data set]. Aqueduct. 


\section{About the Authors}

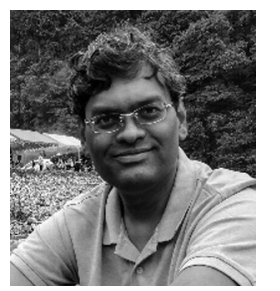

Sivapuram Venkata Rama Krishna Prabhakar (PhD) works as a principal policy researcher at the Institute for Global Environmental Strategies. His research focuses on transboundary climate risks, risk insurance, loss and damage, sustainable and climate smart agriculture, capacity building, vulnerability and risk assessments, and mainstreaming climate change concerns into developmental planning. He has been the contributing author to the IPCC Assessment Report 5 and 6, coordinating lead author and lead author for UNEP Environment Outlooks.

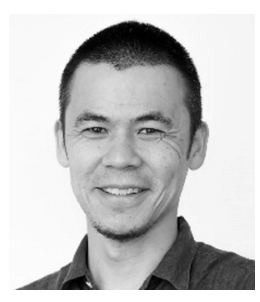

Kentaro Tamura (PhD) is programme director of Climate and Energy Area, Institute for Global Environmental Strategies. After working for the Yokohama National University, he joined Institute for Global Environmental Strategies in 2003. He has centered his research on international cooperation on climate change, and political economy of domestic climate and energy policy. He obtained a PhD in International Relations from the London School of Economics and Political Science (LSE).

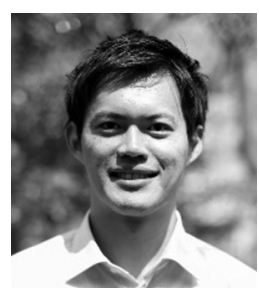

Naoyuki Okano (PhD) is policy researcher at Institute for Global Environmental Strategies, working on climate change adaptation policies. Previously, he was a postdoctoral fellow at the Institute of Social Science, The University of Tokyo, with a research fellowship for young scientists by Japan Society for the Promotion of Science. He obtained a PhD in Comparative Law from Nagoya University Graduate School of Law. His research interest resides in global governance and law, transnational law, legal pluralism, and sociology of law.

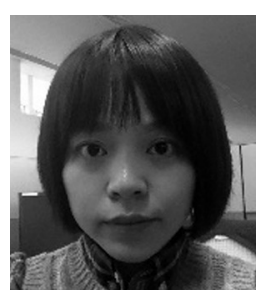

Mariko Ikeda (PhD) worked at the Institute for Global Environmental Strategies as policy researcher. Her interests included disaster risk reduction, climate change adaptation, greenhouse gas mitigation, and sustainable energy. She worked extensively in addressing related policy issues in the Southeast Asian countries and published extensively in these fields. 